\section{An Element of Controversy}

By 1924, all but five of the spaces in the Periodic Table of the Elements had been filled. Two missing elements were in the same column, just under manganese: atomic numbers 43 (now known as technetium, Tc) and 75 (rhenium, Re). The others were 61 (promethium), 85 (astatine), and 87 (francium). The prolonged search for the two elements in the manganese column included many false claims, mostly as a result of impure samples. In 1877, Russian chemist Serge Kern reported that he had found element 43 and named it "davyum," after the chemist Sir Humphrey Davy. In 1908, the Japanese scientist Masataka Ogawa erroneously announced that he had discovered element 43, which he named "nipponim" (as a tribute to his country). However, none of these early "discoveries" held up under scientific scrutiny.

The search for both elements appeared to have ended in 1925. German chemists Walter Noddack; Ida Tacke, later Ida Tacke Noddack; and Otto Berg identified element 75 in a sample of gadolinite and named it rhenium, after the Latin word Rhenus for the Rhine River. Their ability to isolate and analyze a pure sample of rhenium was essential in verifying their discovery.

The same could not be said of element 43, which they had named masurium after Masuria, a region in Prussia. Their evidence in this case was an x-ray spectrograph of a sample of columbite showing a faint peak that they interpreted from theory to belong to element 43 . The facts that they could not isolate the element and that their contemporaries could not reproduce the x-ray spectrograph, however, left their claim open to dispute.

Noddack, Tacke, Berg, and their predecessors were searching for elements the way it had always been done-looking for naturally occurring sources of the material. Little did they know that it would take something akin to alchemy to produce the sample they were seeking.

The alchemy came from nuclear reactions made possible by Ernest O. Lawrence's cyclotron at the University of California, Berkeley. In 1936, physicist Emilio Segrè of the University of Palermo in Sicily visited Lawrence to see the cyclotron first hand; in February 1937, Lawrence sent him a molybdenum foil from the cyclotron's deflector.

"I suspected at once that it might contain element 43," Segrè wrote. "The simple reason was that deuteron bombardment of molybdenum (atomic number 42) should give isotopes of element 43 through well-established nuclear reac-

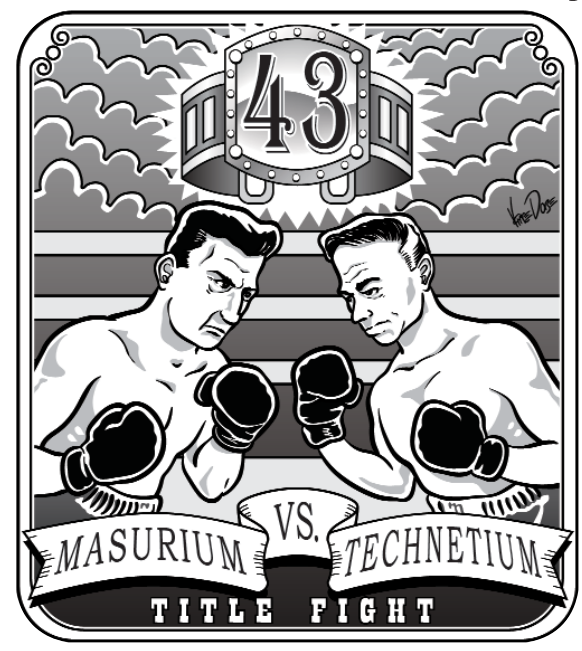

tions." With the help of Carlo Perrier, he succeeded in chemically separating two isotopes. Careful chemical analysis on these minute samples showed that they were indeed element 43 . "In this work we had discovered the first chemical element created by man," Segrè concluded.

Respecting Noddack, Tacke, and Berg's existing claim, Segrè and Perrier made no attempt to rename the element just then. Instead, Segrè visited Noddack's laboratory in Freiburg in 1937 to confer with him about masurium. Noddack said that the the existence of masurium in columbite had been dropped and broken and, so, were unavailable for inspection. Furthermore, Noddack said that the $1 \mathrm{mg}$ of masurium they had succeeded in isolating had been shipped to the Cavendish Laboratory for isotopic analysis. Segrè left Freiburg more skeptical than ever of Noddack's claim.

By 1947, with their own research undisputed and macroscopic amounts of element 43 being produced in nuclear reactors, Segrè and Perrier finally felt comfortable in naming it. In the March 1947 issue of Science, Segrè wrote "It seems appropriate now to give the element the name technetium, from the Greek technetos, artificial, in recognition of the fact that technetium is the first artificially made element." Only in 1964 did B.T. Kenna and P.K Kuroda succeed in isolating $2 \mu \mathrm{g}$ of ${ }^{99} \mathrm{Tc}$ from $1 \mathrm{~kg}$ of African pitchblende, a naturally occurring uranium-based material. They concluded that the element was formed by the spontaneous fission of ${ }^{238} \mathrm{U}$.

So the controversy seemed to have been settled: Noddack could not possibly have found an x-ray peak for element 43 in 1925 because his instrument was not sensitive $\mathrm{x}$-ray plates containing the evidence for enough to detect what would have been, at best, a trace amount of element 43. In 1988, however, Belgian physicist P.H.M. Van Assche published a paper in the journal Nuclear Physics supporting Noddack. He argued that the detection limit for element 43 was $10^{-12} \mathrm{~g}$ using the $\mathrm{x}$-ray equipment available in 1925 , not $10^{-9} \mathrm{~g}$ as reported by Noddack. This reopened the possibility that they had detected element 43.

P.K. Kuroda responded quickly with a paper in the same journal in 1989. Noddack had reported starting with a $1 \mathrm{~kg}$ sample of columbite. Based on calculations of the ratio of Tc to U in columbite, Kuroda estimated that they would have needed at least $50 \mathrm{~kg}$ of columbite to obtain a detectable amount of element 43 . The abstract of his paper says it all: "A careful study of the history of the element 43 covering a period of 63 years since 1925 reveals that there is no reason for believing that the Noddacks and Berg have discovered element 43."

But the renewed controversy did not die there. In a 2003 commentary in Chemical $\mathcal{E}$ Engineering News, John T. Armstrong of the National Institute of Standards and Technology, working with Van Assche, revealed that simulated $x$-ray spectra generated from first-principles x-ray emission algorithms agreed well with the Noddacks' 1925 x-ray spectrum. "We can find no other plausible explanation for the Noddacks' data than that they did indeed detect fission [naturally occurring] 'masurium.'"

In the end, the true discoverer is a moot point by now. There is little chance that technetium would be renamed masurium should the Noddacks' 1925 data be verified at this late date. Noddack, Tacke, and Berg were rightly credited with the discovery of element 75, and Segrè and Perrier found the first undisputed sample of element 43.

In his commentary, Armstrong hit what is undoubtedly the right note: "As a participant in this scientific detective adventure, I'll always have a fondness for the 'element that was discovered twice..."

Tim PALUCKa

For Further Reading: Emilio Segrè, $A$ Mind Always in Motion: The Autobiography of Emilio Segrè (University of California Press, 1993); Otto Hahn, New Atoms: Progress and Some Memories (Elsevier Publishing Company, 1950); Mary Elvira Weeks, Discovery of the Elements, (Division of Chemical Education, American Chemical Society, 1956); and P.K. Kuroda, "A Note on the Discovery of Technetium," Nucl. Phys. A503 (1989) pp. 178-182. 